\section{Р. Мних \\ ЭКСТРЕМАЛЬНОЕ НА ПЕРЕКРЕСТКЕ: ФИЛОСОФИЯ - ИСТОРИЯ - ЛИТЕРАТУРА}

doi: 10.30759/1728-9718-2020-3(68)-55-6o

ББК $87+80$

Статья посвящена анализу категории экстремального в философии, истории и литератуpe, a также возможностям размежевания этого понятия в разных областях гуманитарного знания. Как отдельная категория (метафора или способ фигуративного мышления) экстремальное начинает функционировать в философии Ф. Ницше, хотя оно присутствует в европейской культуре со времен античности. Уже в мифологии экстремальное было связано с чувством страха и состоянием безумия, что нашло свое отражение в «Риторике» Аристотеля и исследованиях, посвященных мистериям в честь бога Диониса. В истории и литературных сюжетах экстремальное присутствует также в ситуациях скандала, который меняет привычный ход истории или является кульминацией сюжета литературного произведения. При этом экстремальное в истории является прежде всего маркером конца старой или начала новой исторической эпохи. В XX в. экстремальное как характеристика бытия человека (преимущественно страха) стало объектом интерпретации М. Хайдеггера в его книге «Бытие и время». Этот же образ страха, передающий пограничные, экстремальные ситуации, характерен и для литературы, например, для поэзии А. Ахматовой. Но если у М. Хайдеггера интерпретация касается прежде всего страха перед смертью, то в поэзии А. Ахматовой преобладает страх перед жизнью. Экстремальное у других русских поэтов XX в., например у А. Блока, символически и семантически связано с проблемой дионисийства.

Ключевые слова: экстремальное, страх, дионисийство, Фридрих Ницие, Мартин Хайдеггер, Александр Блок, Вячеслав Иванов

Я была на краю чего-то, Чему верного нет названья...

Анна Ахматова. Смерть

Кризис позитивистской идеологии под конец XIX в. привел к изменениям в парадигме гуманитарных наук. Одним из самых существенных последствий этих изменений была кардинальная ревизия отношения гуманитариев к тем понятиям и терминам, ${ }^{1}$ которыми они оперировали до этого времени. Начавшаяся еще в европейском романтизме «инфляция» понятийной парадигмы гуманитарных наук во второй половине XIX в. находит своего идеального апологета в лице Фридриха Ницше (18441900). Напомним, что Ф. Ницше был филологом по образованию, философом по призванию и первым деконструктивистом по существу и по своей роли в истории европейской культуры.

\footnotetext{
${ }^{1}$ В области литературоведения в рабочем порядке есть смысл различать слова «понятия» и «термины» по принципу строгой определенности (термины) и неопределенности в дефинициях (понятия). Термины однозначны в дефинициях (ямб, хорей, сонет), в то время как понятия (роман, романтизм, барокко) не обладают такой однозначностью, что позволяет исследователям все время дискутировать по поводу их смысла, а также их реального проявления в литературных практиках.

Мних Роман - д.филол.н., факультет прикладной лингвистики, Варшавский университет (Польша, г. Варшава)

E-mail: r.mnich3@uw.edu.pl
}

Философия XX в. в лице самых видных своих представителей (как западноевропейских, так и русских) отказывается от традиционных философских понятий, предлагая каждый раз новые, образованные в русле той или иной языковой традиции, в зависимости от конкретной ситуации и конкретного мыслителя, а также от личного экзистенциального опыта автора. Неслучайно в XX в. именно в границах европейского экзистенциализма и в русле традиции Ф. Ницше (частично и С. Кьеркегора) в философии, а также в литературоведении и психологии создается абсолютно новая понятийная парадигма. Эта парадигма отражает не только и не столько кризис субъект-объектной парадигмы описания мира, сколько всевозможные попытки описания самого бытия (жизни человека), используя, с одной стороны, метафорический язык, а с другой стороны, разнообразные формы и даже оттенки чувственной сферы человека. Научный язык такого дискурса как бы возвращается в ситуацию дорефлективного мышления древних греков, в первоначальную стихию языка, не обремененную и не ограниченную понятийными абстракциями. Самым ярким примером здесь 
может быть М. Хайдеггер, который, по словам С. Аверинцева, писал вообще «не по-немецки, а по-хайдеггеровски».2

Проблема экстремального не встречается у европейских мыслителей XX в. так часто, как другие понятия или метафоры: совесть, симпатия, тело, желание, граница, растение, след, глубина, путь. Но именно она всякий раз находится в семантическом поле того процесса, который известный немецкий историк понятий и философ Х. Блюменберг назвал метафорологией, а его ученики - «фигуративным знанием». 3 Напомним, что практически во всех европейских языках экстремальное, как правило, выражено двумя основными смыслами: с одной стороны, это семантика крайнего, предельно возможного, верхней границы возможного, а с другой стороны, смысл экстремального связан с семантикой чрезвычайного, необычного, невероятного, исключительного. Оба эти значения коренятся в соответствующем латинском прилагательном (extrēmus), семантика которого, однако, намного богаче: крайний, последний, слабо выраженный (меркнущий), отдаленный, пограничный, заключительный, чрезвычайный, критический, тяжелый, высший, величайший, лучший. ${ }^{4}$

Понятно, что экстремальное в жизни (как событие реальной жизни конкретных людей) становится фактом истории: история меняется и двигается не столько благодаря носу Клеопатры, сколько из-за разных экстремальных ситуаций в судьбах людей, народов, государств. Конечно, и роль отдельной личности в историческом процессе всегда велика, тем более, что именно выдающиеся личности, как правило, очень часто провоцируют экстремальные ситуации (личностные, общественные или государственные). Вспомним также, что именно экстремальное изначально становится темой мифов и литературы, а разные его проявления осмысливаются и рефлексируются философией (а также психологией как частью философии в конце XIX и начале XX в.).

Отметим, что именно по отношению к литературе и искусству понятие экстремального во второй половине XX в. появляется в евро-

\footnotetext{
${ }^{2}$ Ср. слова М. Гаспарова о С. Аверинцеве: «Когда у него была полоса любви к Хайдеггеру, он уговаривал меня: “Почитайте Хайдеггера!” Я отвечал, что слишком плохо знаю немецкий язык. "Но ведь Хайдеггер пишет не по-немецки, а по-хайдеггеровски!” (Гаспаров М. Л. Записи и выписки. М., 2008. С. 109). 3 См. об этом вступительную статью к изданию словаря философских метафор: Wörterbuch der philosophischen Metaphern. Darmstadt, 2014. S. 7-20.

4 См.: Дворецкий И. Х. Латинско-русский словарь. М., 1986. С. 312.
}

пейском философском дискурсе: речь идет о Ф. Ницше. В одном из своих основных (переломных) произведений «Человеческое, слишком человеческое» немецкий философ специально подчеркивал значение экстремального для выражения чувства правды у художника. Речь идет о § 146 («Из души художников и писателей») из четвертого раздела книги:

«Художник имеет более слабую нравственность в отношении познания истины, чем мыслитель; он отнюдь не хочет лишиться права на блестящие, глубокомысленные истолкования жизни и борется против трезвых, простых методов и выводов. Внешне он ратует за высшее достоинство и значение человека; в действительности же он не намерен отказаться от условий, при которых его искусство может производить наибольшее впечатление, т. е. от всего фантастического, мифического, неверного, крайнего (курсив наш - Р. М.), от влечения к символам, от переоценки личности и веры в какую-то чудесную природу гения; он, следовательно, считает сохранение своей манеры творчества более важным, чем научная преданность истинному во всякой, хотя бы и в самой непритязательной, его форме». 5

Таким образом, у Ницше экстремальное (в переводе - крайнее) оказывается одним из тех необходимых творцу произведения искусства аспектов (наряду с мифом и символом), с помощью которых поэт, композитор или художник может производить наибольшее впечатление на реципиента. Мы видим, что в размышлениях Ницше четко прослеживается

5 Ницше Ф. Соч.: в 2 т. М., 1990. Т. 1. С. 324, 325. Приведенное в цитате понятие крайнего в оригинале соответствует понятию экстремального, ср. цитату в оригинале: «Der Wahrheitssinn des Künstler. - Der Künstler hat in Hinsicht auf das Erkennen der Wahrheiten eine schwächere Moralität, als der Denker; er will sich die glänzenden, tiefsinnigen Deutungen des Lebens durchaus nicht nehmen lassen und wehrt sich gegen nüchterne, schlichte Methoden und Resultate. Scheinbar kämpft er für die höhere Würde und Bedeutung des Menschen; in Wahrheit will er die für seine Kunst wirkungsvollsten Voraussetzungen nicht aufgeben, also das Phantastische, Mythische, Unsichere; Extreme, den Sinn für das Symbolische, die Ueberschätzung der Person, den Glauben an etwas Wunderartiges im Genius: er hält also die Fortdauer seiner Art des Schaffens für wichtiger, als die wissenschaftliche Hingebung an das Wahre in jener Gestalt, erscheine diese auch noch so schlicht» (Nietzsche F. Philosophische Werke in sechs Bänden. Erster Band: Menschliches, Allzumenschliches. Hamburg 2013. S. 129, 130). Речь ни в коем случае не идет о критике самого перевода, но в приведенной цитате очень хорошо видны достоинства и ограничения русского варианта этого фрагмента, касающиеся таких понятий, как выводы (в оригинале - Resultate), крайнее (в оригинале - Extreme), неверное (в оригинале - Unsichere, то есть небезопасное, ненадежное), влечение (в оригинале Sinn, то есть чувство) и т. д. Проблема в том, что перечисленные понятия функционируют в текстах Ницше в других семантических плоскостях, нежели их русские корреляты по отношению к русскому философскому дискурсу. 
противопоставление экстремального, с одной стороны, и трезвого, простого, с другой: таким способом и в русле платоновской традиции противопоставляются трезво мыслящие философы безумствующим художникам и поэтам.

Если мы попробуем теперь проанализировать, как понятие экстремального функционирует в европейской мысли после Ницше, то заметим, что чаще всего оно появляется вместе с понятием страха. Именно страх, а также его разные аспекты и семантические оттенки оказываются тем экстремальным чувством, которое определяет, как это ни странно, идейное содержание множества литературных и философских текстов, а также является двигателем истории XX в. Мы можем очень многие исторические события свести к первичному чувству страха основных персонажей этих событий: страх Николая I отразился в наказании декабристов, страх Александра III превратился в усиление административного давления и реакцию, страх Ленина спровоцировал расстрел царской семьи, страх Сталина провоцировал террор. Вспомним и повсеместное чувство страха во время Второй мировой войны, в свете событий которой бесстрашие и героизм представляют собой обратную сторону того же страха. На чувстве страха держится, очевидно, любая власть, это чувство определяет часто отношения между поколениями в семье и социальными группами в обществе.

Возвращаясь к европейской философской традиции, отметим, что одним из самых ярких последователей, а заодно и интерпретаторов философии Ф. Ницше был М. Хайдеггер. И в данном случае особенно поражает тот факт, что именно понятие страха у М. Хайдеггера исследователи связывают напрямую с проблемой и понятием экстремального. Современный немецкий культуролог и социолог Н. Больц, анализируя знаменитые пассажи о страхе в «Бытии и времени» прямо пишет о том, что мысль М. Хайдеггера в его эпохальной книге «устремлена в экстремальное», то есть в чувство страха ("geht in die Extreme, nämlich die Angst"). ${ }^{6}$

Понятие страха в немецкой классической философии впервые начинает активно фигу-

\footnotetext{
${ }^{6}$ Bolz N. Ungebrochene Faszination, in: Neunzig Jahre < Sein und Zeit $>$. Herausgegeben von Harald Seubert. Freiburg; München, 2019. S. 41. В немецком языке для обозначения страха существуют два слова, оба женского рода: Angst и Furcht. Coответствующий, 30-й параграф в книге Хайдеггера называетcя "Die Furcht als ein Modus der Befindlichkeit" (Heidegger M. Sein und Zeit. Tübingen, 1993. S. 140-142). Понятно, что этот пассаж в книге немецкого философа был предметом множества комментариев.
}

рировать у немецких романтиков, особенно у Ф. В. Й. Шеллинга, и весьма характерно, что оно отсутствует как в старом, ${ }^{7}$ так и в новом словаре И. Канта. ${ }^{8}$ В мировоззрении Шеллинга избежание страха (то есть устранение экстремальной ситуации) связывается с сущностью комедии, ${ }^{9}$ а «ужас утраты всякого сознания единства» ${ }^{10}-$ с религиозной верой. Конечно, в связи с понятием страха как одного из самых существенных экзистенциальных проявлений экстремального мы должны вспомнить и С. Кьеркегора с его знаменитой формулой «страх есть обморок свободы». ${ }^{11}$ Заметим только, что даже в этом парадоксе датского философа обморок - это тоже экстремальное состояние.

Таким образом, при всем разнообразии языков описания экстремального в XX в. одним из самых существенных и центральных понятий будет понятие страха. Интересно отметить, что Хайдеггер, размышляя о страхе в своей книге, ссылается на соответствующий раздел «Риторики» Аристотеля, где древнегреческий философ подробно описывает виды страха и способы его воздействия на поведение человека. ${ }^{12}$ Однако у Аристотеля чувство страха рассматривается как составляющая риторики, в то время как у М. Хайдеггера страх превращается в одну из основополагающих экзистенциальных характеристик бытия человека и интерпретируется в основном как страх перед смертью. ${ }^{13}$ Но Аристотель, как и М. Хайдеггер, обращаясь к анализу чувства страха, рассматривает экстремальные состояния человека, переломные периоды в его жизни и кризисные ситуации.

Очевидно, принципиальная разница между философской и литературной рефлексией экстремального, особенно в свете философии М. Хайдеггера, кроется в тематизации этого феномена: в философии тема касается страха

\footnotetext{
7 CM.: Eisler R. Kant-Lexikon. Nachschlagewerk zu Kants sämtlichen Schriften, Briefen und handschriftlichem Nachlaß. Berlin, 1930.

${ }^{8}$ Cм.: Irrlitz G. Kant-Handbuch. Leben und Werk. Stuttgart, 2010.

9 См.: Шеллинг Ф. В. Й. Философия искусства. М., 1966. С. 419.

${ }^{10}$ Он же. Соч.: в 2 т. М., 1989. T. 2. С. 255.

${ }^{11}$ См. интерпретацию этой проблемы: Шестов Л. Киргегард и экзистенциальная философия (Глас вопиющего в пустыне). M., 1992. C. $115^{-122 .}$

${ }_{12}$ См. раздел о страхе в «Риторике» Аристотеля: Аристотель. Риторика. Поэтика. М., 2007. С. 76-79.

${ }_{13}$ Характерна в этом отношении ссылка Хайдеггера на повесть Л. Н. Толстого «Смерть Ивана Ильича» - единственное за всю книгу упоминание русской литературы (Heidegger M. Op. cit. S. 254). В то же время другой русский классик Ф. М. Достоевский был тем писателем, который, по словам современных исследователей и комментаторов Хайдеггера, «выводил» немецкого философа из аристотелизма (Heidegger - Handbuch. Stuttgart, 2005. S. 58).
} 
перед смертью, в то время как в литературе страх перед смертью часто уступает страху перед жизнью. Именно страх в жизни и страх перед самой жизнью становятся предметом осмысления и изображения во многих текстах русской поэзии XX в., что связано с трагедиями, экстремальными историческими и личностными ситуациями. Вспомним репрезентацию этой проблемы у А. Ахматовой: от «Северных элегий» («В том доме было очень страшно жить») до знаменитого стихотворения «Страх, во тьме перебирая вещи, // Лунный луч наводит на топор».14 Ярким примером текста, в котором соединились концепты смерти, страха и бесстрашия (смелости) является также и стихотворение И. Бродского «На смерть Жукова», повествующее о щедро проливавших солдатскую кровь маршалах, которые «смело входили в чужие столицы, но возвращались в страхе в свою». ${ }^{15}$

В литературе, как, впрочем, и в истории, мы можем обнаружить семантические и символические корреляции между страхом и такими понятиями (феноменами), как скандал или безумие. Здесь нужно, конечно, вспомнить изданные Н. Букс сборники, посвященные семиотике страха, безумия и скандала, ${ }^{16}$ в которых собран богатейший литературный, искусствоведческий, исторический, социологический, а также философский материал по интересующей нас теме. Эти сборники являются также ярким примером того, как понятие и само чувство экстремального репрезентировано в конкретных текстах культуры и литературы и, самое главное, как по-разному люди (авторы и читатели, создатели и реципиенты созданного) понимают и воспринимают экстремальное в его ярчайших проявлениях: страхе, безумии, скандале. В связи со сказанным нужно вспомнить и известный текст Ю. Лотмана, посвященный семиотике страха и стыда. ${ }^{17}$ Конечно, оба эти эк-

\footnotetext{
14 Ахматова А. А. Соч.: в 2 т. М., 1990. Т. 1. С. 162, 261 (курсив в цитате наш - P. M.). О лейтмотиве страха в «Северных элегиях» см.: Mnich R. Жанровая эволюция элегии в литературе XX века. Siedlce, 2015. C. 113-116.

15 Бродский И. А. Стихотворения и поэмы. СПб., 2011. Т. 1. C. 345,346 (курсив в цитате наш - P. M.); см. также комментарий к этому стихотворению: Там же. С. 588-591.

16 См.: Семиотика страха. Париж; М., 2005; Семиотика безумия. Париж; М., 2005; Семиотика скандала. М.; Париж, 2008. В русле нашей проблематики особый интерес представляет статья историка Михаила Геллера, посвященная страху (см.: Семиотика страха. Париж; М., 2005. С. 400-404). ${ }_{17}$ См.: Лотман Ю. М. О семиотике понятий «стыд» и «страх» в механизме культуры // Лотман Ю. М. Статьи по семиотике культуры и искусства. СПб., 2002. С. 435-438. Отметим парадоксальное совпадение: именно проблеме страха и стыда посвящены два раздела (пятый и шестой) второй книги «Риторики» Аристотеля.
}

зистенциальные состояния представляют экстремальное в жизни человека: они выражают, как пишет Лотман, сферу ограничений, накладываемых на поведение человека определенным типом культуры. Ограничения (запреты) касаются как юридических, так и моральных норм поведения, они являются также и маркерами пограничных (экстремальных) ситуаций, выражающих принципиальные аспекты межчеловеческих отношений.

Для русской культурной традиции XX в. особенно важным является и такой аспект экстремального, как дионисийство во всех его проявлениях. Самые важные тексты, как и сами кульминационные этапы в развитии русского дионисийства (от романов Ф. М. Достоевского до книг Вяч. Иванова и творчества русских символистов ${ }^{18}$ ), мы можем описать также с помощью понятия экстремального. Экстремальное напрямую выражает суть дионисийского экстаза, его связь с безумием, частично страхом и скандалом (в этимологическом значении слова

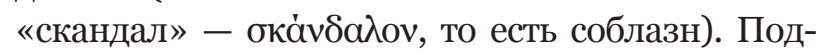
тверждением таких размышлений может быть поэзия А. Блока, во всяком случае, лирика третьего тома (циклы «Страшный мир», «Возмездие», «Ямбы» и др.): есть смысл рассматривать ее именно как поэзию экстремального.

Предложенный подход, конечно, поднимает очень широкую проблему связи экстремального с русским символизмом, вернее, места экстремального в поэтической системе русского символизма. Не пытаясь решать проблему глобально, попробуем для примера прочитать в русле обозначенного проекта три строфы из известного стихотворного послания А. Блока «Вячеславу Иванову»:

Был скрипок вой в разгаре бала.

Вином и кровию дыша,

В ту ночь нам судъбы диктовала

Восстанья страшная душа.

Из стран чужих, из стран далёких

В наш огнь вступивши снеговой,

В кругу безумных, томнооких

Ты золотою встал главой. <...>

Был миг - неведомая сила,

Восторгом разрывая грудь,

Сребристым звоном оглушила,

Секучим снегом ослепила,

Блаженством исказила путь! ${ }^{19}$

\footnotetext{
18 Сейчас нет возможности анализировать проблему русского дионисийства во всей ее широте, укажем только на самые значимые публикации на эту тему (раздел «Под знаком Диониса») в книге: Иванов Вяч. Pro et contra: антология: в 2 т. СПб., 2016. Т. 2. С. $84-170$.

19 Блок А. А. Полн. собр. соч. и писем: в 20 т. М., 1997. Т. 3: Стихотворения. Книга третья (1907-1916). С. 99 (курсив в цитате
} 
С одной стороны, в цитируемых строфах представлены самые характерные образы русского символизма вообще и А. Блока в особенности: скрипки, вино, кровь, ночь, судьба, огонь, снег, восторг, звон. Но, с другой стороны, практически все эти образы-символы в их художественном воплощении выражают именно экстремальное как философскую, а в данном случае, и поэтическую, категорию. «Вой скрипок» - это, конечно же, не простая игра на скрипке, но дионисийская по своей сути музыка, так же, как и "рыдание скрипок», «стон скрипок» или «скрипок голоса запредельные». ${ }^{20}$ Аналогично дионисийскими по символике и экстремальными по сути являются образы вина и крови в их глубинном мифологическом и евхаристическом значении, равно как и образы судьбы и страха в первой строфе стихотворения. Таким же экстремальным предстает и характерное для поэтики Блока соединение жара и холода, огня и снега - «огня снегового» во второй строфе. Аналогичный по семантике и символике - дионисийский, мистический и экстремальный - образный мир третьей строфы, причем здесь дионисийство в, так сказать, «чистом виде»: «разорванная восторгом грудь», глухота, слепота, но при этом блаженство на новом пути - полный набор для характеристики дионисийских мистерий.

Мы можем для подтверждения приведенных мыслей привести соответствующие цитаты из исследования Вяч. Иванова «Эллинская религия страдающего бога». Русский поэт и философ пишет о «феномене дионисийского безумия», об «огненном море религиозных экстазов», о дионисийском превращении, которое «открывает перед экстатическим взором новый мир», наконец, о том, что даже «трагедия - дионисийское действие, и как таковое, аналогична безумию». ${ }^{21}$ Если в литературе и искусстве

\footnotetext{
наш - P. M.). Ср. также комментарии к этому тексту: Там же. C. 796-799.

20 Остается, конечно, вопросом для исследователей, насколько в цикле Блока «Арфы и скрипки» представлена проблема дионисийства и по какому принципу поэт противопоставляет/соединяет арфу и скрипку; если арфу понимать как инструмент, родственный лире, то напрашивается само собой противопоставление Аполлона и Диониса, см.: «Если арфа у Блока связана с гармоническим, упорядоченным образом мира (в мифологии арфа (лира) - атрибут Аполлона), то скрипка скорее соответствует дионисийскому началу в жизни и искусстве» (Блок А. А. Полн. собр. соч. и писем. Т. 3. С. 823). ${ }_{21}$ Текст книги Вяч. Иванова «Эллинская религия страдающего бога» цит. по изданию: Символ. Журнал христианской культуры. 2014. № 64. С. 73, 74, 78, 79. Парадоксальным образом пассаж из этой книги может служить комментарием и к знаменитому стихотворению Блока, посвященному А. Ахматовой («“Красота страшна”, - Вам скажут...»). Красота по Вяч. Иванову - это древний восторг, трагедия, пере-
}

экстремальное становится темой и отчасти сущностью творчества, то в истории оно связано прежде всего с проблемой начал и концов: государств и империй, великих исторических периодов, жизней отдельных исторических персонажей. Как правило, именно экстремальные ситуации сигнализируют о конце старой или, наоборот, начале новой исторической эпохи.

Самая существенная и, по всей видимости, не так легко решаемая проблема - это проблема границ понятия экстремального, которая оборачивается простым вопросом: а что, собственно, не является в культуре или истории экстремальным? Какие случаи можно рассматривать и интерпретировать одновременно как экстремальные и как не-экстремальные, то есть естественные? Революция 1917 г. (или большевистский переворот), например, - это проявление экстремального в истории или же закономерного? Если историки и теоретики литературы называют события 1917 г. «переломом», ${ }^{22}$ то понятие перелома в истории культуры - это следствие экстремальных событий или же это проявление другого рода закономерностей? Аналогичные вопросы мы можем задать и о феномене карнавала в истории культуры, который сами участники могут регулярно организовывать в Венеции, но могут также быть вовлечены в карнавал событиями, от них не зависящими. По всей видимости, на уровень экстремального выходит и ежегодное празднование христианской Пасхи, у истоков которой стоит распятие Иисуса как кульминационный (экстремальный) пункт в истории человечества. Все эти и подобные им проблемы порождают фундаментальные вопросы о естественном и неестественном в культуре и истории; они связаны с проблемой логики в развитии культуры и истории, с логикой мифа (если таковая существует) и логикой символа и открывают широкую перспективу для дальнейших исследований в области гуманитарных наук.

дающая экстремальную ситуацию, которая возвращает нас к религиозному всепостижению: «С нами - красота: ею может возродиться древний освободительный, очистительный, все разверзающий восторг; она сильна возродить нас к религиозному всепостижению. Быть может, снова возникает из лона музыки истинная трагедия...» (Там же. С. 74).

${ }^{22}$ См.: Перелом 1917 года: революционный контекст русской литературы. Исследования и материалы. М., 2017. 


\begin{abstract}
Roman Mnich
Doctor of Philological Sciences, University of Warsaw (Poland, Warsaw)

E-mail:r.mnich3@uw.edu.pl
\end{abstract}

\title{
THE EXTREME AT THE CROSSROADS: PHILOSOPHY - HISTORY - LITERATURE
}

The article is devoted to the analysis of the extreme as a notion in philosophy, history and literature, as well as the possibilities of delimiting this notion in different areas of humanities. As a concept (metaphor or way of figurative thinking), the extreme begins its functioning in the philosophy of F. Nietzsche, although it has been present in European culture from antiquity. Already in mythology, the extreme was associated with a sense of fear and a state of madness, which was reflected in Aristotle's "Rhetoric" and studies on the Dionysian mysteries. In history and literary plots, the extreme is also present in situations of scandal, which changes the usual course of history or is the climax of a plot of a literary work. Moreover, the extreme in history is primarily a marker of the end of an old or the beginning of a new historical era. In the $20^{\text {th }}$ century, the extreme as a characteristic of human being (fear par excellence) became the object of interpretation by M. Heidegger in his book "Being and Time". Image of fear, expressing borderline, extreme situations is also characteristic of literature, for example, A. Akhmatova's poetry. But if M. Heidegger's interpretation primarily concerns the fear of death, then the fear of life predominates in the poetry of A. Akhmatova. The extreme in the works of other Russian poets of the $2 \mathrm{O}^{\text {th }}$ century, for example, A. Blok, is symbolically and semantically associated with the problem of Dionysianism.

Keywords: extreme, fear, Dionysianism, Friedrich Nietzsche, Martin Heidegger, Alexandr Blok, Vyacheslav Ivanov

\section{REFERENCES}

Bolz N. Ungebrochene Faszination. Neunzig Jahre >Sein und Zeit<. Freiburg; München: Verlag Karl Alber, 2019, ss. 26-42. (in German).

Dvoretskiy I. Kh. Latinsko-russkiy slovar' [Latin-Russian Dictionary]. Moscow: Russkiy yazyk Publ., 1986. (in Russ.).

Eisler R. Kant-Lexikon. Nachschlagewerk zu Kants sämtlichen Schriften, Briefen und handschriftlichem Nachlaß. Berlin: Georg Olms Verlag, 1994. (in German).

Heidegger M. Sein und Zeit. Tübingen: Max Niemeyer Verlag, 1993. (in German).

Heidegger - Handbuch. Stuttgart: Verlag J. B. Metzler, 2005. (in German).

Irrlitz G. Kant-Handbuch. Leben und Werk. Stuttgart: Verlag J. B. Metzler, 2010. (in German).

Ivanov Vyach. [The Hellenic religion of the suffering God]. Simvol. Zhurnal khristianskoy kul'tury [Symbol. Journal of Christian Culture]. Paris; Moscow: Institut Sv. Fomy Publ., 2014, no. 64. (in Russ.).

Ivanov Vyach. Pro et contra: antologiya: $v 2 t$. [Pro et contra: anthology: in 2 vols.]. Saint Petersburg: Rossiyskaya gumanitarnaya akademiya Publ., 2016, vol. 2. (in Russ.).

Lotman Yu. M. Stat'i po semiotike kul'tury i iskusstva [Articles on the semiotics of culture and art]. Saint Petersburg: "Akademicheskiy proyekt” Publ., 2002. (in Russ.).

Mnich R. Zhanrovaya evolyutsiya elegii $v$ literature XX veka [Genre evolution of elegy in the $20^{\text {th }}$ century literature]. Siedlce: Instytut Kultury Regionalnej i Badań Literackich im. Franciszka Karpińskiego Publ., 2015. (in Polish).

Perelom 1917 goda: revolyutsionnyy kontekst russkoy literatury. Issledovaniya i materialy [The turning point of 1917: the revolutionary context of Russian literature. Studies and materials]. Moscow: IMLI RAN Publ., 2017. (in Russ.).

Schelling F. W. J. Filosofiya iskusstva [Philosophy of art]. Moscow: Mysl' Publ., 1966. (in Russ.).

Schelling F. W. J. Sochineniya: $v 2 t$. [Works: in 2 vols.]. Moscow: Mysl' Publ., 1989, vol. 2. (in Russ.).

Semiotika bezumiya [Semiotics of madness]. Paris: Sorbonna. Rus. in-t Publ.; Moscow: Europe Publ., 2005. (in Russ.).

Semiotika skandala [Semiotics of scandal]. Moscow: Europe Publ.; Paris: Sorbonna. Rus. in-t Publ., 2008. (in Russ.).

Semiotika strakha [Semiotics of fear]. Paris: Sorbonna. Rus. in-t Publ.; Moscow: Europe Publ., 2005. (in Russ.).

Shestov L. Kirgegard i ekzistentsial'naya filosofiya (Glas vopiyushchego $v$ pustyne) [Kierkegaard and existential philosophy (A voice crying in the desert)]. Moscow: "Progress"-“Gnozis" Publ., 1992. (in Russ.).

Wörterbuch der philosophischen Metaphern. Darmstadt: Wissenschaftliche Buchgesellschaft, 2014. (in German). 